\title{
Long term outcomes of Burch colposuspension and transobturator tape and single incision needleless (DynaMesh $₫$ - SIS minor) for the surgical treatment of female stress urinary incontinence patients who underwent combined pelvic reconstructive surgery or hysterectomy
}

Yesim Akdemir ( $\sim$ yesimakdemir@yahoo.com)

Zonguldak Bulent Ecevit Universitesi Tip Fakultesi https://orcid.org/0000-0002-8574-5065

Fadime Dincer

Zonguldak Bulent Ecevit Universitesi Tip Fakultesi

Cagatay Buyukuysal

Zonguldak Bulent Ecevit Universitesi Tip Fakultesi

Ulku Ozmen

Zonguldak Bulent Ecevit Universitesi Tip Fakultesi

Muge Harma

Zonguldak Bulent Ecevit Universitesi Tip Fakultesi

Mehmet Ibrahim Harma

Zonguldak Bulent Ecevit Universitesi Tip Fakultesi

Research article

Keywords: Burch colposuspension, Concomitant surgery, Pelvic reconstructive surgery, Single incision sling, Stress urinary incontinence, Transobturator tape

Posted Date: April 30th, 2020

DOl: https://doi.org/10.21203/rs.2.21791/v3

License: (c) (1) This work is licensed under a Creative Commons Attribution 4.0 International License. Read Full License 


\section{Abstract}

Background: Women with stress urinary incontinence (SUI) often require combined pelvic reconstructive surgeries because of shared risk factors of pelvic organ prolapse The purpose of this study is to evaluate the efficacies of Burch colposuspension, the transobturator tape (TOT), and single-incision needleless (DynaMesh®-SIS minor) procedures in patients with SUI who also underwent combined pelvic reconstructive surgery or hysterectomy.

Methods: We performed this prospective cohort study that comprising 142 patients who either underwent Burch colposuspension (n:43), TOT(n:40), or SIS(n:39) procedures along with pelvic reconstructive surgery or hysterectomy between January 2010 and July 2018. During the clinical follow-up, we analyzed the objective and subjective cure rates, improvement rates, along with failure and surgical success rates of SUI surgery. We assessed quality of life and symptom severity by Incontinence Impact Questionnaire (IIQ-7), Urogenital Distress Inventory (UDI-6), Sandvik Severity Index (SSI), Surgical Satisfaction Questionnaire (SSQ-8), Overactive Bladder Questionnaire V8 (OAB-V8), and Patient Global Impression of Improvement (PGI-I) scale scores. The primary outcome was surgical success, which was established when there was an improvement in patients or when the patients achieved objective or subjective cure, whereas secondary outcomes included intraoperative bladder injury, sling extrusion, de novo urgency, voiding dysfunction, length of hospital stay, and patient-reported outcomes in the quality of life questionnaires.

Results: Surgical success rates were higher in the Burch group than the SIS group and also higher in the TOT group than in the SIS group ( $88.4 \%$ vs $61.5 \%$ and $87.5 \%$ vs $61.5 \%$ respectively, $p=0.003$ ) The complaints of urinary incontinence were higher and quality of life was lower in the SIS group than in the Burch group. In terms of IIQ-7, UDI-6, OAB-V8, SSI, and SSQ-8 scores, no difference was observed between Burch and TOT groups, and TOT and SIS groups.

Conclusions: Both Burch and TOT are safe and effective procedures in patients with SUI who require additional pelvic surgeries. Although the surgical outcomes of SIS procedure in patients with SUI who underwent concomitant pelvic surgeries in our study were not promising, further randomized studies are needed to clarify these observations due to unclear data.

\section{Background}

Stress urinary incontinence (SUI) is the complaint of involuntary loss of urine on effort or physical exertion including sporting activities, or on sneezing or coughing (1). The prevalence of SUI is $46 \%$ in women of reproductive age in Turkey (2). Women with SUI often require combined pelvic reconstructive surgeries, because of shared risk factors of pelvic organ prolapse such as obesity, pregnancy, and childbirth, or hysterectomy for other gynecological pathologies (3).

Burch colposuspension was considered as the gold standard surgical treatment before Ulmsten and Petros (4) presented the tension-free vaginal tape (TVT) procedure in 1995 and, consecutively, Delorme 
(5) practiced the transobturator tape (TOT) (outside-in) procedure in 2001. Several observational and randomized studies have showed similar efficacy and lower morbidity for mid-urethral sling (MUS) procedures than Burch colposuspension (6-9). However, Burch colposuspension is still a frequently performed and effective surgical procedure for SUI, especially when there is a need for concomitant pelvic surgery. With the advancements in laparoscopic techniques, laparoscopic Burch colposuspension is gaining popularity as a non-mesh alternative, minimally invasive SUI surgery, which also provides equal effectiveness as an open surgery (10).

While being rare, bladder, vaginal, urethral, and vascular perforations or erosions, and groin pain are reported after MUS procedures (11). To minimize these risks, single-incision slings (SIS) that avoid retropubic or obturator space entry were developed in 2006 (12). Despite the potential advantages of SIS, the reported cure rate ranges between $48 \%$ and $88 \%$ in the follow-up of two to five years (13-18).

The purpose of this study is to evaluate the efficacies of Burch colposuspension, TOT, and SIS (DynaMesh ${ }^{\circledR}$ SIS minor) procedures in patients with SUI, who also underwent combined pelvic reconstructive surgery or hysterectomy.

\section{Methods}

This is a prospective cohort study that evaluated women with SUI or stress-predominant mixed urinary incontinence who underwent Burch colposuspension, TOT, or SIS procedures along with pelvic reconstructive surgery or hysterectomy between January 2010 and July 2018 in the Gynecology Clinic at Zonguldak Bulent Ecevit University, School of Medicine.

The inclusion criteria of this study were the presence of clinically proven SUI by stress test, failed medical treatment or pelvic floor training, and a postoperative follow-up duration of 12 months or more. The exclusion criteria were: history of incontinence surgery, presence of urge-predominant mixed urinary incontinence, peripheral neuropathy, multiple sclerosis, history of urogenital cancer, kidney and renal failures, severe cardiac disease and history of cerebrovascular accident. We examined the clinical history of each patient. Then, we conducted pelvic examination and POP-Q staging, and identified other gynecological pathologies in the patients. Preoperative urodynamic studies were not routinely performed and SUI was diagnosed by identifying positive stress test with a filled bladder.

The patients who were diagnosed with abnormal uterine bleeding, uterine leiomyoma, or pelvic organ prolapse underwent surgeries such as total abdominal hysterectomy (TAH), vaginal hysterectomy $(\mathrm{VH})$, anterior colporrhaphy (AC), posterior colporrhaphy (PC), rectus fascia colpopexy (RFC), and/or unilateral sacrospinous ligament fixation (SSF). At the end of these procedures, either Burch colposuspension, TOT, or SIS was performed. Three senior surgeons almost equally performed all the procedures. If the surgeon decided to perform hysterectomy via the abdominal route, then he/she performed Burch colposuspension in most cases $(40 / 44,90.9 \%)$. TOT or SIS procedures were performed if consent for Burch colposuspension was not provided by the patient. The same criteria were valid for the vaginal approach. 
If the surgeon decided to perform hysterectomy via the vaginal route, then he/she performed TOT or SIS procedure $(32 / 32,100 \%)$ in the consecutive patients.

Burch colposuspension was performed as originally described by placing bilateral two sutures between the ipsilateral iliopectineal ligaments and vaginal wall at the levels of mid-urethra and urethravesical junction (19). The TOT procedure was performed according to Delorme (4) which is an outside to inside method. The SIS procedure was performed by using DynaMesh $®$ - SIS minor, which is a non-absorbable, fluoropolymer, polyvinylidene fluoride (PVDF) sling (20). After performing the sharp bilateral paraurethral dissection up to bilateral pubic rami, DynaMesh ${ }^{\circledR}$ - SIS minor was attached by self-attaching surface without any additional fixation device. Cystoscopy was performed after all the Burch colposuspension procedures. On the contrary, cystoscopy was only performed after the TOT procedure if there was a suspicion of bladder and/or urethral injury. A Foley catheter was placed and removed after $24 \mathrm{~h}$ unless an $\mathrm{AC}$ procedure was performed. We measured post-void urine volume, and the patient was discharged if residue was less than $100 \mathrm{ml}$.

We evaluated the patients at 1, 6,12 months, and annually after the surgical interventions. Additionally, we conducted stress test, Q-tip test, detailed urogynecological examination, including groin and anterior vaginal mucosa for possible sling exposure, and POP-Q staging. We recorded any symptom that was relevant with the procedures and outcomes of patient-reported and Turkish language-validated versions of Incontinence Impact Questionnaire (IIQ-7) (21) and Urogenital Distress Inventory (UDI-6) (21), Sandvik Severity Index (SSI) (22), Surgical Satisfaction Questionnaire (SSQ-8) (23), Overactive Bladder Questionnaire V8 (OAB-V8) (24), and Patient Global Impression of Improvement (PGI-I) Scale (25). Objective cure of SUI was defined when the stress test was negative in the lithotomy position with a full bladder and patient-reported continence. However, the subjective cure of SUI was defined as the presence of positive stress test and patient-reported continence. Improvement was assessed with PGI-I Scale and defined when the answers were a little better, much better, and very much better (25). Failure was defined as the presence of positive stress test and patient-reported incontinence, along with persisted or recurrent SUl after surgery. At last, surgical success was defined when improvement was reported in the patients or when the patients achieved objective or subjective cure.

Secondary outcomes included intraoperative bladder injury, sling extrusion, de novo urgency, voiding dysfunction, length of hospital stay, and patient-reported outcomes in the quality of life questionnaires.

\section{Statistical analysis}

SPSS 19.0 was used for statistical analysis. Continuous values were presented with mean, standard deviation, median, minimum and maximum values, where categorical variables were presented with frequency and percent. Shapiro Wilk test were used for test of normality. Kruskal Wallis test used for variables group comparisons of continuous variables. Pearson Chi-Square tests were used for comparison of categorical variables among groups. All statistical comparisons with a $p$ value below 0.05 were assumed as statistically significant. 


\section{Ethics statement}

An ethics committee report was obtained from the School of Medicine, Zonguldak Bulent Ecevit University. Written informed consent was obtained from all individual participants for whom identifying information is included in this article.

\section{Results}

We evaluated 43, 40 and 39 women in Burch, TOT, and SIS groups, respectively. The mean follow-up time in Burch, TOT, and SIS groups were $20.97 \pm 12.72,32.05 \pm 19.5$, and $13.69 \pm 4.48$ months, respectively. No significant differences were observed among the groups in terms of age, body mass index, parity, number of vaginal deliveries, menopausal status, comorbidities (hypertension and diabetes mellitus, chronic obstructive pulmonary disease), and smoking (Table 1). Types of urinary incontinence were similar among the groups. Stress-predominant mixed urinary incontinence was the most common type of incontinence in all the groups $(67.4 \%, 80 \%$, and $84.6 \%$ in Burch, TOT, and SIS groups, respectively). The most performed concomitant procedure was TAH in the Burch group (90.9\%), along with AC in TOT (38.29\%) and SIS groups (47.05\%; Table 1).

Pelvic hematoma, urinary retention, or recurrent urinary infection were not observed in either of the groups after any of the procedures. Table 2 presents the list of complications. Sling extrusion was higher in the SIS group than in the TOT group [six cases (15.4\%) vs two cases (5.15\%), p: 0.008]. The two cases in the TOT group were continent and referred for dyspareunia in the second and tenth postoperative months. Sling was trimmed locally with local anesthesia. No other interventions were required in both the cases, and the patients remained continent during follow-up. Three of the six cases in the SIS group referred in the first six months presented with incontinence and vaginal discomfort. Sling extrusion was identified after six postoperative months during follow-up in three other cases that were continent. Bladder injury, voiding dysfunction, and de novo urgency rates (no de novo urgency was observed after SIS procedures) were similar among the groups (Table 2). The length of hospital stay was significantly higher in the Burch group than in the TOT and SIS groups $(3.06 \pm 2.58,2.20 \pm 2.26$, and $1.92 \pm 1.56$ in Burch, TOT and SIS groups, respectively).

The objective cure rates were higher in Burch and TOT groups than in the SIS group (53.5\%, $65 \%$, and $30.85 \%$ in Burch, TOT and SIS groups, respectively, p: 0.008; Table 3). The subjective cure rates and the improvement rates were similar among the groups. Surgical success rates were higher in Burch and TOT groups than in SIS group (88.4\%, 87.5\%, and 61.5\% in Burch, TOT and SIS groups, respectively, p: 0.003). There was no statistical significance between Burch and TOT groups in terms of objective cure, subjective cure, improvement, failure, and surgical success rates.

The complaints of urinary incontinence were higher, whereas the quality of life was lower in the SIS group than in the Burch group. IIQ-7, UDI-6, OAB-V8, and SSI scores were significantly higher in the SIS group than in the Burch group (Table 3). SSQ-8 scores, which positively related with surgical satisfaction, were higher in the Burch group than in the SIS group ( $82.58 \pm 24.71$ vs $65.13 \pm 24.80$, p: 0.01$)$. There was no 
difference between Burch and TOT groups, and TOT and SIS groups in terms of IIQ-7, UDI-6, OAB-V8, SSI, and SSQ-8 scores.

On the contrary, PGI-I scores, which were negatively related with cure and improvement, were higher in the SIS group than in Burch and TOT groups. No differences were observed between Burch and TOT groups in terms of PGI-I scores (Table 3).

We investigated the persistence of urgency with $O A B-V 8$. The patients with $O A B-V 8$ scores $\geq 12$ were diagnosed with postoperative overactive bladder (21). Although we could not classify persistent urgency as de novo urgency, we found that postoperative overactive bladder rates were lower in the Burch group than in the SIS group ( $47.6 \%$ vs $84.6 \%$, respectively, p: 0.002$)$ and similar preoperative stress-predominant mixed incontinence rates existed in all the groups.

To clarify the relationship between surgical success and overactive bladder or SUI symptoms and quality of life, we further compared the patients with surgical success and patients with failure (Table 4). Not surprisingly, IIQ-7, UDI-6, OAB-V8, SSI, and PGI-I scores were significantly lower whereas SSQ-8 scores were higher in patients with surgical success.

\section{Discussion}

Because of the common etiology, it is not surprising that almost half of the women with SUl underwent additional pelvic surgeries with incontinence surgeries $(26,27)$. Nevertheless, there is currently no consensus regarding the surgical treatment of SUI in patients who require concomitant surgical procedures for pelvic organ prolapse or benign uterine pathologies. In this study, we found that $88.4 \%$, $87.5 \%$, and $61.5 \%$ of women with SUI who had concurrent pelvic reconstructive surgery or hysterectomy were benefited from Burch colposuspension, TOT, and DynaMesh ${ }^{\circledR}$ - SIS minor mini-slings, respectively.

Mellier et al. found that the cure rate, which was considered as the complete absence of incontinence and was obtained via UDI-6 and IIQ-7 scores at a median of 17 months, were $73 \%$ in patients who underwent TOT (Monarch ${ }^{\circledR}$ ) alone and $57 \%$ in patients who underwent TOT and other surgeries including VH, AC, PC, and vaginal vault suspension (28). They reported that sling extrusions and infections rates were similar in both of groups, but severe voiding dysfunction only occurred in the TOT-only group.

Additionally, they concluded that TOT procedure can be safely applied with concomitant vaginal procedures (28). In the case series of Lo, 51 patients who had advanced pelvic prolapse and SUI were treated with TOT (Monarch ${ }^{\circledR}$ ) and vaginal genital reconstructive surgery. In total, $86 \%$ of these patients were cured of incontinence at 12 months (29). Similarly, we found that the surgical success rate of TOT procedure was $87.5 \%$ at a median of 28 months in our study.

Burch colposuspension is an effective incontinence procedure, especially when the abdominal route is used for hysterectomy. However, Moon et al. compared the efficacies of Burch colposuspension and TOT in patients who underwent concomitant abdominal hysterectomy and abdominal sacrocolpopexy (ASC) and found that the cure rate was significantly higher in patients who underwent TOT with ASC than 
patients who underwent Burch colposuspension with ASC (69\% and $98 \%$, respectively) (30). The authors speculated that extensive traction on the bladder neck made by ASC mesh and Burch colposuspension could be the reason of the failures and de novo urgency. On the contrary, little or no effect of Burch colposuspension on postoperative failures, de novo overactive bladder, or voiding dysfunction was demonstrated in a recent Cochrane review (31). In our study, four out of 43 patients underwent Burch colposuspension for SUI with RFC for vaginal vault suspension, and surgical success was obtained in three out of four patients at 16 months, which was coherent with the surgical success rate of Burch colposuspension group.

Although SIS procedure could be performed with concomitant pelvic reconstructive surgery, data is scarce. Most of the studies that reported results of SIS procedure in patients with SUI excluded the patients with pelvic prolapse $(16,18,32)$. Fernandez-Gonzalez et al. included patients with pelvic prolapse in their study, which compared SIS (Contasure needless ${ }^{\circledR}$ ) with TOT (Monarch $\AA$ ) in the treatment of SUI. They found that Contasure needless ${ }^{\circledR}$ was not inferior to Monarch $\AA(15)$. However, they did not separately analyze the surgical outcomes of patients with pelvic prolapse as a subgroup. We performed SIS procedure with DynaMesh ${ }^{\circledR}$ minor after completing the reconstructive surgery. To our knowledge, this is the first study that reports the surgical outcomes of SIS and compares three different procedures to treat SUI in patients who underwent concomitant pelvic surgeries.

Most of the early studies revealed that SIS (TVT Secur® was the largest sample) procedure had a higher incontinence rate and a higher chance of requiring repeated incontinence surgery than the TOT procedure $(33,34)$. Because of these medicolegal issues and inferior results of early trials, many SIS procedures were withdrawn from the hospital settings. Nevertheless, SUI procedures with newer SIS are promising. A randomized controlled study that compared SIS (Contasure-needleless ${ }^{\circledR}$ ) with TOT (Contasure-KIM ${ }^{\circledR}$ ) found that both procedures were comparable in terms of the objective/subjective cure and failure rates (16). In their randomized trial, Sivaslioglu et al. demonstrated better results with Tissue Fixation minisling procedure than TOT procedure in patients with urodynamically proven SUI (17). Yildiz et al. reported high success rates with Ophira mini-sling system at a follow-up of three years. They reported that the objective cure and failure rates were $83 \%$ and $9.8 \%$, respectively (32). Moreover, Gambini-Ricapa et al. published high urodynamically proven cure rate after endopelvic free anchor mini-sling procedures at long follow-up and suggested that the success of the mini-sling technique was due to retropubic insertion route of sling to endopelvic fascia and pelvic diaphragm (18).

Contrary to the above studies, we found inferior objective cure and surgical success rates and higher failure rates in the SIS (DynaMesh ${ }^{\circledR}$ SIS minor) group than both Burch and TOT groups in our study. Inferiority was not observed between Burch and TOT groups. However, we recommend that results of our study need a careful interpretation. First, the material of the SIS was PVDF which is a non-absorbable, fluoropolymer monofilament, and it is different from the above-mentioned studies (that most commonly used polypropylene ). There is a paucity of data in literature regarding the use of PVDF slings in urinary incontinence procedures. While Padilla-Fernandez et al. reported less tolerance and less success rates of PVDF slings in TOT procedures (35), Sabadell et al. demonstrated similar efficacy and safety of PVDF 
slings with polypropylene slings (36). Currently, there are no studies that compare PVDF with polypropylene SIS. Second, Nambiar et al. concluded that the fixation mechanism of SIS was crucial, and poor performance of the withdrawn SIS might due to the lack of specific fixation systems (34).

DynaMesh ${ }^{\circledR}$ SIS minor is a short sling that has self-attaching surface and was used without the need of any additional fixation device. Third, on December 2018, The Independent Medicines and Medical Devices Safety Review published that FEG Textiltechnik would be globally removing DynaMesh ${ }^{\circledR}$ SIS minor in the near future. Importantly, the reason to remove the product was not affected by an undesired clinical result and would not be carried out under the scope of a Field Safety Corrective Action (37). This action of FEG Textiltechnik will limit the further comparative studies. Third, we believe that all of the concomitant surgeries (hysterectomy either abdominal or vaginal, AC or Apical Suspension surgeries) could affect the success of the incontinence surgeries due to change in anatomy and by affecting pelvic support and continence. But we are aware of the concomitant pelvic surgeries had a broad spectrum among the three groups, which could invoke bias in the interpretation of results and complications. Hysterectomy rates were also not comparable among the groups $(90.9 \%, 40.42 \%$, and $33.33 \%$ in Burch, TOT, and SIS groups, respectively). However, vaginal concomitant procedures and approaches were more common in TOT and SIS groups. We have to mention that, because of PC is not an operation that can affect the results of incontinence procedures in our study, it was not performed as a single concomitant procedure. Instead, all PC procedures were performed with VH and AC.

Recently, the National Institute for Health Research of UK published ESTHER systematic review to evaluate the clinical effectiveness, safety, and cost effectiveness of surgical treatments of SUI (38). Their study reported that the cure rates at 12 months were $89.1 \%, 76.7 \%, 64.1 \%$, and $39.8 \%$ for TVT, TOT, Burch colposuspension, and SIS, respectively. The need for repeat surgeries was higher in the TOT group than in the TVT (18.3\% vs $0.5 \%)$ group and as well as higher in the SIS group than in the TOT ( $5.1 \%$ vs $2.9 \%)$ group. Although there was considerable uncertainty around the estimation of effects, voiding difficulties were higher in the patients who had Burch colposuspension than in patients who had TOT (OR: 1.96), and higher in patients who had TOT than in patients who had SIS (OR: between 0.34 and 0.93). While comparing the sling extrusion rates, similar results were obtained for a short term between SIS and TOT (4.8\% vs $3.7 \%)$, but long-term results favored TOT again with uncertainty (OR: 2.43-5.02). The results of our study also showed that the voiding dysfunction rate was similar among the three groups, and the sling extrusion was higher in the SIS group than in the TOT group during long term. High rates of mesh extrusion in SIS might due to patient-related risk factors, that is, all patients who had mesh extrusion in the SIS group were in menopause, were grand multipara (parity $\geq 5$ ), or had a possible inferior tolerance of PVDF sling.

Another conflicting issue is the uncertainty about the optimum predictor of successful treatment. Despite the ease of assessment and objectivity of negative stress test, patients' subjective impressions regarding cure and improvement might be more important. According to this observation, some studies only used validated questionnaires or women's self-reports to assess the cure rates $(28,38)$. Majority of studies demonstrated both women's subjective cure and improvement by the quality of life questionnaires or simply examined satisfaction rate and objective cure by negative stress test $(6,15-18,32,39-41)$. On the 
contrary, Lo preferred to only report objective cure rate and results of urodynamic investigations (29). In our opinion, patients' subjective impressions of cure and improvement, objective cure that defines negative stress test, and patient's quality of life assessments with validated questionnaires are crucial and should be evaluated together.

Furthermore, the worsening of urge symptoms or persistent urgency might deteriorate patient's quality of life, even when they are objectively cured. Domingo et al. concluded that mixed incontinence was not improved which was assessed by the quality of life questionnaires after TOT procedure and the main reason was patients' worsening urge symptoms (39). Likewise, we found that OAB-V8 scores were lower in patients with surgical success than in patients with failure, and the rate of overactive bladder after surgery was higher in the SIS group, which was also associated with the lowest surgical success rate.

The strengths of our study are as follows: we compared Burch colposuspension, TOT, and SIS procedures to treat SUI in patients who underwent concomitant pelvic surgeries for the first time. Our study had relatively longer follow-up periods, and we used validated questionnaires to evaluate patients' quality of life and also determined all objective and subjective cure, improvement, failure, and surgical success rates.

Despite the insights provided by our study, it is not free from limitations. We did not obtain the quality of life assessments before surgery. The study group includes all the patients with pure SUI or stresspredominant mixed urinary incontinence. This inclusion criterion might introduce bias during the evaluation of patient's quality of life in terms of urgency symptoms. The concomitant pelvic surgeries belonged to a wide spectrum. We could not perform urodynamic studies; therefore, we could not exclude the patients with intrinsic sphincter deficiency, which could also serve as a possible bias.

\section{Conclusions}

In conclusion, we found that Burch colposuspension and TOT procedures were more efficacious than SIS (DynaMesh ${ }^{\circledR}$ SIS minor) procedure in patients with SUI, who also underwent combined pelvic reconstructive surgery or hysterectomy. The quality of life scores were also higher in patients who underwent Burch colposuspension or TOT procedures than in the patients who underwent SIS (DynaMesh ${ }^{\circledR}$ SIS minor) procedure. After considering the results of this study, we conclude that both Burch and TOT are safe and effective procedures in patients with SUI who required additional pelvic surgeries and either could be applied by selecting the route of surgery. Although the surgical outcome of SIS (DynaMesh ${ }^{\circledR}$ SIS minor) procedure in SUI patients who underwent concomitant pelvic surgeries in our study was not promising, further randomized studies are needed to clarify these observations due to unclear data.

\section{Abbreviations}

TOT: transobturator tape 
SUI: stress urinary incontinence

SIS: single-incision needleless

IIQ-7: Incontinence Impact Questionnaire

UDI-6: Urogenital Distress Inventory

SSI: Sandvik Severity Index

SSQ-8: Surgical Satisfaction Questionnaire

OAB-V8: Overactive Bladder Questionnaire V8

PGI-I: Patient Global Impression of Improvement

TVT: tension-free vaginal tape

MUS: mid-urethral sling

TAH: total abdominal hysterectomy

VH: vaginal hysterectomy

AC: anterior colporrhaphy

PC: posterior colporrhaphy

RFC: rectus fascia colpopexy

SSF: sacrospinous ligament fixation

PVDF: polyvinylidene fluoride

ASC: abdominal sacrocolpopexy

\section{Declarations}

Ethics approval and consent to participate: An ethics committee report was obtained from the School of Medicine, Zonguldak Bulent Ecevit University. Written informed consent was obtained from all individual participants for whom identifying information is included in this article.

Consent for publication: N/A

Availability of data and materials: The datasets used and/or analysed during the current study are available as a submitted seperate file but only usable on reasonable request from the corresponding author. 
Competing interests: The authors declare that they have no competing interests

Funding: This manuscript has no funding.

\section{Authors' contributions:}

YA: Study conception and design, Acquisition of data, Analysis and interpretation of data, Drafting of manuscript, Critical revision

FD: Drafting of manuscript

CB: Analysis and interpretation of data

UO: Acquisition of data, Performed surgeries, Critical revision

$\mathrm{MH}$ : Acquisition of data, Performed surgeries Critical revision

$\mathrm{MH}$ : Acquisition of data, Performed surgeries Critical revision

\section{All authors read and approved the final manuscript}

Acknowledgements: N/A

\section{References}

1. D'Ancona C, Haylen B, Oelke M et al. The International Continence Society (ICS) report on the terminology for adult male lower urinary tract and pelvic floor symptoms and dysfunction. Neurourol Urodyn. 2019 Feb;38(2):433-477.

2. Onur R, Deveci SE, Rahman S, Sevindik F, Acik Y. Prevelence and risk factors of Female urinary incontinence in eastern Turkey. Int J Urol. 2009 Jun;16(6):566-9.

3. Veit-Rubin N, Cartwright R, Singh AU, Digesu GA, Fernando R, Khullar V. Association between joint hypermobility and pelvic organ prolapse in women: a systematic review and meta-analysis Int Urogynecol J. 2016 Oct;27(10):1469-78

4. Ulmsten U, Petros P. Intravaginal slingplasty (IVS): an ambulatory surgical procedure for treatment of female urinary incontinence. Scand J Urol Nephrol 1995;29(1):75-82.

5. Delorme E. Transobturator urethral suspension: mini-invasive procedure in the treatment of stress urinary incontinence in women. Prog Urol 2001;11(6):1306-13.

6. Asıcıoglu O, Gungorduk K, Besımoglu B, Ertas IE, Yıldıım G, Celebı I, Ark C, Boran B. A 5-year follow-up study comparing Burch colposuspension and transobturator tape for the surgical treatment of stress urinary incontinence. Int J Gynaecol Obstet. 2014 Apr;125(1):73-7

7. Sivaslioglu AA, Caliskan E, Dolen I, Haberal A. A randomized comparison of transobturator tape and Burch colposuspension in the treatment of female stress urinary incontinence. Int Urogynecol $\mathrm{J}$ 
Pelvic Floor Dysfunct. 2007 Sep;18(9):1015-9.

8. Lapitan MC, Cody JD. Open retropubic colposuspension for urinary incontinence in women. Cochrane Database Syst Rev.2012 Jun 13;(6):CD002912.

9. Ward KL, Hilton P; UK and Ireland TVT Trial Group. Tension-free vaginal tape versus colposuspension for primary urodynamic stress incontinence: 5-year follow up. 2008 Jan;115(2):226-33.

10. Veit-Rubin N, Dubuisson J, Ford A, Dubuisson JB, Mourad S, Digesu A. Burch colposuspension. Neurourol Urodyn.2019 Feb;38(2):553-562.

11. Ford AA, Rogerson L, Cody JD, Aluko P, Ogah JA. Mid-urethral sling operations for stress urinary incontinence in women. Cochrane Database Syst Rev. Jul 31;7:CD006375.

12. Moore R et al. Retrospective review of early experience using the AMS Mini Arc single incision sling system to treat estres urinary incontinence in women. J Minim Invasive Gynecol 2007 14:129- 130

13. Basu M, Duckett J. Three-year results from a randomised trial of a retropubic mid-urethral sling versus MiniArc single incision sling for stress urinary incontinence. Int Urogynecol J 2013 12: 20592064

14. Cornu JN, Sebe P, Peyrat L, Ciofu C, Cussenot O, Midtherm HF. Prospective evaluation of TVT secur reveals high failure rate. Eur Urol 2010 58:157-161

15. Fernandez-Gonzalez S, Martinez Franco E, Lin Miao X, Amat Tardiu L. Contasure-needleless ${ }^{\circledR}$ compared with Monarc $®$ for the treatment of stress urinary incontinence. Int Urogynecol J. 2017 Jul;28(7):1077-1084.

16. Dogan O, Kaya AE, Pulatoglu C, Basbug A, Yassa M. A randomized comparison of a single-incision needleless (Contasure-needleless ${ }^{\circledR}$ ) mini-sling versus an inside-out transobturator (Contasure-KIM ${ }^{\circledR}$ ) mid-urethral sling in women with stress urinary incontinence: 24-month follow-up results. Int Urogynecol J. 2018 Sep;29(9):1387-1395.

17. Sivaslioglu AA, Unlubilgin E, Aydogmus S, Keskin L, Dolen I. A prospective randomized controlled trial of the transobturator tape and tissue fixation mini-sling in patients with stress urinary incontinence: 5-year results. J Urol. 2012 Jul;188(1):194-9.

18. Gambini-Ricapa J, García-Oms J, Barea M, Estrada A, Iturri A, Gambini-Buchon J, Gilabert-Estelles J. Endopelvic free anchor minisling technique for stress urinary incontinence treatment: 10 years of experience. Int Urogynecol J. 2016 Aug;27(8):1265-72.

19. Walters MD, Karram MM (1993) Clinical urogynecology. Mosby, USA

20. Klinge U, Klosterhalfen B, Ottinger AP, Junge K, Schumpelick V. PVDF as a new polymer for the construction of surgical meshes. Biomaterials 2002; 23: 3487- 3493.

21. Cam C, Sakalli M, Ay P, Cam M, Karateke A. Validation of the short forms of the incontinence impact questionnaire (IIQ-7) and the urogenital distress inventory (UDI-6) in a Turkish population. Neurourol Urodyn. 2007;26(1):129-33. 
22. Sandvik H, Espuña M, Hunskaar S. Validity of the incontinence severity index: comparison with padweighing tests. Int Urogynecol J. 2006;17:520-4.

23. E. Haff, J. Stoltzfus, V.R. Lucente, M. Murphy. The Surgical Satisfaction Questionnaire (SSQ-8): A Validated Tool for Assessment of Patient Satisfaction Following Surgery To Correct Prolapse and/or Incontinence. Journal of Minimally Invasive Gynecology 201118(6):S49-S50 · November 2011

24. Acquadro C, Kopp Z, Coyne KS, et al. Translating overactive bladder questionnaires in 14 languages. Urology. 2006; 67: 536- 540.

25. Yalcin I, Bump RC. Validation of two global impression questionnaires for incontinence. Am J Obstet Gynecol. 2003 Jul;189(1):98-101.

26. Tanussino KF, Kanzal E, Kolk D, Ralph G, Riss PA. Tension-free vaginal tape operation: results of the Austrian Registry. Obstet Gynecol 2001 98:732-736

27. Huang KH, Kung FT, Liang HM, Hang LY, Chang SY. Concomitant surgery with tension-free vaginal tape. Acta Obstet Gynecol Scand 2003 82:948-953.

28. Mellier G, Mistrangelo E, Gery L, Philippe C, Patrice M.Tension-free obturator tape (Monarc Subfascial Hammock) in patients with or without associated procedures. Int Urogynecol J (2007) 18: 165-172.

29. Lo Tsia-Shu. Combined Pelvic Reconstructive Surgery and Transobturator Tape (Monarc) in Women with Advanced Prolapse and Urodynamic Stress Incontinence: A Case Control Series. Journal of Minimally Invasive Gynecology 2009 16, 163-166.

30. Moon YJ, Jeon MJ, Kim SK, Bai SW. Comparison of Burch colposuspension and transobturator tape when combined with abdominal sacrocolpopexy. Int J Gynaecol Obstet. 2011 Feb;112(2):122-5.

31. Baessler K, Christmann-Schmid C, Maher $C$ et al. Surgery for women with pelvic organ prolapse with or without stress urinary incontinence. Cochrane Database Syst Rev 2018;(8): CD013108.

32. Yildiz G, Ceylan Y, Ucer O, Arslan D, Çelik O, Gunlusoy B. Safety and efficacy of single-incision sling for female stress urinary incontinence: 3 years' results. Int Urogynecol J. 2016 Nov;27(11):16671671.

33. Mostafa A, Lim CP, Hopper L, Madhuvrata P, Abdel-Fattah M. Single-incision mini-slings versus standard midurethral slings in surgical management of female stress urinary incontinence: an updated systematic review and meta-analysis of effectiveness and complications. Eur Urol. 2014 Feb;65(2):402-27.

34. Nambiar A, Cody JD, Jeffery ST, Aluko P. Single-incision sling operations for urinary incontinence in women. Cochrane Database Syst Rev. 2017 Jul 26;7:CD008709.

35. Padilla-Fernández B, García-Cenador MB, Gómez-García A, Mirón-Canelo JA, Gil-Vicente A, SilvaAbuín JM, Lorenzo-Gómez MF. Results of the surgical correction of urinary stress incontinence according to the type of transobturator tape utilized. Arch Ital Urol Androl. 2013 Sep 26;85(3):149-53.

36. Sabadell J, Larrain F, Gracia-Perez-Bonfils A, Montero-Armengol A, Salicrú S, Gil-Moreno A, Poza JL. Comparative study of polyvinylidene fluoride and polypropylene suburethral slings in the treatment of female stress urinary incontinence. J Obstet Gynaecol Res. 2016 Mar;42(3):291-6. 
37. The Independent Medicines and Medical Devices Safety Review. December 2018. Available at http://www.immdsreview.org.uk

38. Brazzelli M, Javanbakht M, Imamura M, Hudson J, Moloney E, Becker F, et al. Surgical treatments for women with stress urinary incontinence: the ESTER systematic review and economic evaluation. Health Technol Assess 2019;23(14).

39. Domingo S, Alamá P, Ruiz N, Lázaro G, Morell M, Pellicer A. Transobturator tape procedure outcome: a clinical and quality of life analysis of a 1-year follow-up. Int Urogynecol J Pelvic Floor Dysfunct. 2007 Aug;18(8):895-900.

40. Bandarian M, Ghanbari Z, Asgari A. Comparison of transobturator tape (TOT) vs Burch method in treatment of stress urinary incontinence. Journal of Obstetrics and Gynaecology 2011 31:6, 518-520.

41. Yasa C, Gungor Ugurlucan F, Dural O, Yumru H, Gunaydin C, Yalcin O. Transobturator Tape Operation for the Treatment of Stress Urinary Incontinence in Postmenopausal Women Aged Over 65 Years. Low Urin Tract Symptoms. 2018 May;10(2):153-157.

\section{Tables}

Table 1 Demographic and clinical parameters of patients. 


\begin{tabular}{|c|c|c|c|c|}
\hline & $\begin{array}{l}\text { Burch } \\
(n: 43)\end{array}$ & $\begin{array}{c}\text { TOT } \\
(\mathrm{n}: 40)\end{array}$ & $\begin{array}{c}\text { SIS } \\
(\mathrm{n}: 39)\end{array}$ & p value ${ }^{1}$ \\
\hline Duration of follow-up(mo) ${ }^{\square}$ & $20,97 \pm 12,72$ & $32,05 \pm 19,55$ & $13,69 \pm 4,48$ & $<0,001^{2}$ \\
\hline $\mathrm{Age}^{\square}$ & $50,76 \pm 10,86$ & $52,05 \pm 9,57$ & $52,38 \pm 8,48$ & 0,845 \\
\hline $\mathrm{BMI}^{\mathrm{a}, \mathrm{a}}$ & $32,65 \pm 8,01$ & $31,13 \pm 5,03$ & $30,36 \pm 4,48$ & 0,418 \\
\hline Parity ${ }^{\square}$ & $2,69 \pm 1,05$ & $3,35 \pm 1,51$ & $3,38 \pm 1,61$ & 0,149 \\
\hline Vaginal delivery $^{\square}$ & $2,97 \pm 1,27$ & $3,17 \pm 1,70$ & $3,30 \pm 1,70$ & 0,062 \\
\hline Menopausal status $\mathrm{n}(\%)$ & $20(46,5)$ & $21(52,5)$ & $18(46,2)$ & 0,815 \\
\hline \multicolumn{5}{|l|}{ Comorbidities n(\%) } \\
\hline \multicolumn{5}{|l|}{$\mathrm{HT}^{\mathrm{b}}$} \\
\hline $\mathrm{DM}^{\mathrm{c}}$ & $15(39,4)$ & $19(47,5)$ & $20(51,3)$ & 0,289 \\
\hline \multirow[t]{2}{*}{$\operatorname{COPD}^{\mathrm{d}}$} & $5(11,6)$ & $10(25)$ & $3(7,7)$ & 0,074 \\
\hline & $0(0)$ & $3(7,5)$ & $3(7,7)$ & 0,068 \\
\hline Smoking $n(\%)$ & $7(16,8)$ & $7(17,5)$ & $12(30,8)$ & 0,215 \\
\hline \multicolumn{5}{|c|}{ Urinary incontinence type $\mathrm{n}(\%)$} \\
\hline \multicolumn{5}{|c|}{ SUI ${ }^{\mathrm{e}}$} \\
\hline \multicolumn{5}{|l|}{ Mixt } \\
\hline & $14(32,6)$ & $8(20)$ & $6(15,4)$ & 0,157 \\
\hline & $29(67,4)$ & $32(80)$ & $33(84,6)$ & \\
\hline \multicolumn{5}{|l|}{ Concomitant procedure $\mathrm{n}(\%)$} \\
\hline \multicolumn{5}{|l|}{$\mathrm{TAH}^{\mathrm{f}}$} \\
\hline \multicolumn{5}{|l|}{$\mathrm{VH}^{\mathrm{g}}$} \\
\hline$A C^{h}$ & $40(90,9)$ & $3(6,38)$ & $1(1,96)$ & \\
\hline $\mathrm{PC}^{1}$ & 0 & $16(34,04)$ & $16(31,37)$ & \\
\hline$R F C^{j}$ & 0 & $18(38,29)$ & $24(47,05)$ & \\
\hline \multirow[t]{3}{*}{$\mathrm{SSF}^{\mathrm{k}}$} & 0 & $6(12,76)$ & $9(17,64)$ & \\
\hline & $4(9,09)$ & $0(0)$ & $1(1,96)$ & \\
\hline & $0(0)$ & $4(8,51)$ & $0(0)$ & \\
\hline
\end{tabular}

${ }^{\square}$ Data presented as mean $\pm \mathrm{SD}$

${ }^{a}$ body mass index, ${ }^{b}$ hypertension, ${ }^{c}$ diabetes mellitus, ${ }^{d}$ chronic obstructive pulmonary disease, ${ }^{e}$ stress urinary incontinence, $\mathrm{f}$ total abdominal hysterectomy, $\mathrm{g}$ vaginal hysterectomy, $\mathrm{h}$ anterior colporrhaphy, ${ }^{\mathrm{l}}$ posterior colporrhaphy, ${ }^{\mathrm{j}}$ rectus fascia colpopexy, ${ }^{\mathrm{k}}$ sacrospinous ligament fixation

${ }^{1}$ Chi-square test, ${ }^{2} \mathrm{p}$ value for each double comparisons

Table 2 Intraoperative and postoperative complications during follow up. 


\begin{tabular}{|c|c|c|c|c|}
\hline & $\begin{array}{l}\text { Burch } \\
(n: 43)\end{array}$ & $\begin{array}{c}\text { TOT } \\
(n: 40)\end{array}$ & $\begin{array}{c}\text { SIS } \\
(\mathrm{n}: 39)\end{array}$ & p value ${ }^{a}$ \\
\hline Mesh extrusion n(\%) & $0(0)$ & $2(5,1)$ & $6(15,4)$ & $0,008^{1}$ \\
\hline Bladder injury $\mathbf{n}(\%)$ & $1(2,3)$ & $1(2,5)$ & $0(0)$ & 0,459 \\
\hline De novo urgency n(\%) & $3(7)$ & $2(5)$ & $0(0)$ & 0,129 \\
\hline Voiding dysfunction & $9(21,4)$ & $9(22,5)$ & $9(23,1)$ & 0,984 \\
\hline Hospital stay length (days) ${ }^{\square}$ & $3,06 \pm 2,58$ & $2,20 \pm 2,26$ & $1,92 \pm 1,56$ & $<0,001^{2}$ \\
\hline
\end{tabular}

${ }^{\mathrm{a} C h i}$-square test. ${ }^{\square}$ Data presented as mean $\pm \mathrm{SD}$.

${ }^{1} \mathrm{p}$ value for comparison between TOT and SIS.

${ }^{2} \mathrm{p}$ value for comparisons between Burch and SIS, and between Burch and TOT.

Table 3 Surgical and patient reported outcomes.

\begin{tabular}{|c|c|c|c|c|}
\hline & $\begin{array}{l}\text { Burch } \\
(n: 43)\end{array}$ & $\begin{array}{c}\text { TOT } \\
(\mathrm{n}: 40)\end{array}$ & $\begin{array}{c}\text { SIS } \\
(\mathrm{n}: 39)\end{array}$ & p value ${ }^{a}$ \\
\hline Objective cure n(\%) & $23(53,5)$ & $26(65)$ & $12(30,8)$ & $0,008^{1}$ \\
\hline Subjective cure $n(\%)$ & $6(14)$ & $5(12,5)$ & $6(15,4)$ & 0,934 \\
\hline Improvement n(\%) & $9(20,9)$ & $4(10)$ & $6(15,4)$ & 0,390 \\
\hline Failure n(\%) & $5(11,6)$ & $5(12,5)$ & $15(38,5)$ & $0,003^{1}$ \\
\hline Surgical success $n(\%)$ & $38(88,4)$ & $35(87,5)$ & $24(61,5)$ & $0,003^{1}$ \\
\hline OAB n(\%) & $20(47,6)$ & $28(70)$ & $33(84,6)$ & $0,002^{2}$ \\
\hline IIQ-7 $7^{\square}$ & $24,49 \pm 28,41$ & $34,14 \pm 32,59$ & $48,57 \pm 32,41$ & $0,002^{2}$ \\
\hline UDI- $6^{\square}$ & $26,32 \pm 23,21$ & $33,83 \pm 25,33$ & $45,98 \pm 28,65$ & $0,005^{2}$ \\
\hline OAB-V8 ${ }^{\square}$ & $10,90 \pm 9,32$ & $15,25 \pm 11,13$ & $19,69 \pm 11,25$ & $0,001^{2}$ \\
\hline $\mathrm{SSI}^{\mathbb{1}}$ & $3,90 \pm 3,95$ & $5,17 \pm 4,84$ & $7,38 \pm 4,41$ & $0,002^{2}$ \\
\hline SSQ-8 $8^{\square}$ & $82,58 \pm 24,71$ & $78,15 \pm 19,75$ & $65,13 \pm 24,80$ & $0,01^{2}$ \\
\hline PGI-I ${ }^{\square}$ & $2,14 \pm 1,04$ & $2,40 \pm 1,46$ & $3,30 \pm 1,00$ & $<0,001^{1}$ \\
\hline
\end{tabular}

${ }^{\square}$ Data presented as mean $\pm \mathrm{SD}$

${ }^{\mathrm{a} C h i-s q u a r e ~ t e s t . ~}$

${ }^{1} \mathrm{p}$ value for comparisons between Burch and SIS, and between TOT and SIS, ${ }^{2} \mathrm{p}$ value for comparisons between Burch and SIS.

Table 4 Comparison of quality of life and urinary incontinence in patients with surgical success and failure. 


\begin{tabular}{lccc} 
& $\begin{array}{c}\text { Surgical Success } \\
(\mathrm{n}: 97)\end{array}$ & $\begin{array}{c}\text { Failure } \\
(\mathrm{n}: 25)\end{array}$ & p value $^{\mathrm{a}}$ \\
\cline { 1 - 3 } IIQ-7 $^{\square}$ & $31,03 \pm 31,03$ & $53,27 \pm 32,50$ & 0,001 \\
\hline UDI-6 $^{\square}$ & $30,65 \pm 24,74$ & $53,19 \pm 27,76$ & $<0,001$ \\
\hline OAB-V8 $^{\square}$ & $13,29 \pm 10,28$ & $22,75 \pm 11,21$ & $<0,001$ \\
\hline SSI $^{\square}$ & $4,28 \pm 4,10$ & $10,16 \pm 3,39$ & $<0,001$ \\
\hline SSQ-8 $^{\square}$ & $81,60 \pm 20,72$ & $50,95 \pm 21,85$ & $<0,001$ \\
\hline PGI-I $^{\square}$ & $2,17 \pm 0,94$ & $4,33 \pm 0,96$ & $<0,001$
\end{tabular}

${ }^{\mathrm{a} C h i}$-square test.

\section{Supplementary Files}

This is a list of supplementary files associated with this preprint. Click to download.

- STROBEchecklistcohort.pdf

- DATASET.xlsx 